\title{
DNA binding protein A expression and methylation status in hepatocellular carcinoma and the adjacent tissue
}

\author{
MAHMUT YASEN $^{1,4}$, GULANBAR OBULHASIM ${ }^{3,4}$, KAZUNORI KAJINO $^{3}$, KAORU MOGUSHI $^{2}$, \\ HIROSHI MIZUSHIMA $^{2}$, SHINJI TANAKA ${ }^{1}$, HIROSHI TANAKA ${ }^{2}$, OKIO HINO $^{3}$ and SHIGEKI ARII ${ }^{1}$ \\ Departments of ${ }^{1}$ Hepato-Biliary-Pancreatic Surgery and ${ }^{2}$ Computational Biology and Bioinformatics, \\ Tokyo Medical and Dental University, Tokyo 113-8510; ${ }^{3}$ Department of Pathology and Oncology, \\ Juntendo University School of Medicine, Tokyo 113-8421, Japan; ${ }^{4}$ Department of Surgery, Xinjiang \\ Uyghur Tumor Hospital of Xinjiang Medical University, Xinjiang 830011, P.R. China
}

Received August 17, 2011; Accepted September 15, 2011

DOI: $10.3892 /$ ijo.2011.1282

\begin{abstract}
We investigated the expression and promoter methylation of $\mathrm{dbpA}$ in human hepatocellular carcinoma (HCC) and examined their correlation with clinicophathological features. In 96 paired samples of HCC and adjacent non-tumorous liver, and 10 normal liver specimens, dbpA mRNA was quantified by real-time RT-PCR, and promoter methylation was examined by methylation-specific polymerase chain reaction and bisulfite sequencing. The results showed that dbpA mRNA expression levels were higher in HCC compared to corresponding non-tumor tissues $(\mathrm{P}<0.01)$ and higher in non-virus-associated HCC compared to virusassociated cases $(\mathrm{P}<0.01)$. dbpA promoter was methylated in $37.7 \%$ of HCC samples and the promoter methylation was significantly correlated with the low expression of $\mathrm{dbpA}$ in non-virus-associated $\mathrm{HCC}(\mathrm{P}<0.01)$, but not in virus-associated HCC. Surprisingly, poor prognosis was more significantly associated with high dbpA expression in non-tumorous liver $(\mathrm{P}=0.018)$ but not with that in HCC. Non-tumorous tissues consist of chronic hepatitis or liver cirrhosis, and these conditions are the background of hepatocarcinogenesis, defined as the hypercarcinogenic state. Our results suggest that the high expression of $\mathrm{dbpA}$ in the hypercarcinogenic state is an indicator of poor prognosis.
\end{abstract}

Correspondence to: Dr Mahmut Yasen, Department of HepatoBiliary-Pancreatic Surgery, Tokyo Medical and Dental University, 1-5-45 Yushima, Bunkyo-ku, Tokyo 113-8510, Japan

E-mail: mahmut@bioinfo.tmd.ac.jp

Abbreviations: HCC, hepatocellular carcinoma; HBV, hepatitis B virus; $\mathrm{HCV}$, hepatitis $\mathrm{C}$ virus; qRT-PCR, quantitative real-time reverse transcription PCR; 5-AzaC, 5-Aza-2-deoxycytidine; MS-PCR, methylation-specific polymerase chain reaction

Key words: hepatocellular carcinoma, DNA binding protein A, prognosis, promoter methylation

\section{Introduction}

Hepatocellular carcinoma (HCC) is the sixth most common cancer in the world and the 5-year survival rate of individuals with $\mathrm{HCC}$ is lower in $10 \%$, because of its poor prognosis $(1,2)$. It is particularly common in China, Japan, Africa and is also recently increasing in Western countries and USA (3-5). The etiological factors for HCC are well-defined. Hepatitis B virus and hepatitis $\mathrm{C}$ virus infection, toxicant exposure, cigarette smoking, alcohol consumption and also metabolic diseases contribute well-documented risk factors for the development of HCC $(6,7)$. In addition, numerous genetic abnormalities associated with the development of HCC have been described. However, the detailed molecular mechanism for the development and progression of HCC is not clear yet (8).

As for other tumors, development of HCC is due to a multistep process with accumulation of genetic and epigenetic alteration in regulatory genes (9-14). CpG Island may be a fundamental contributor to carcinogenesis and cancer progression (15-17). Such epigenetic defects also have been observed in non-cancerous liver tissue of HCC patients. The aberrant methylation observed in HCC may be a consequence of the normal aging process, persistent viral infection or chronic inflammation (18).

DNA binding protein A (dbpA) belongs to the Y-box binding protein family. It is located on chromosome 12 and the molecular weight of dbpA protein is approximately $60 \mathrm{kDa}$. The cold-shock domain, which is highly conserved from bacteria to human and contain about 70 amino acid residues, is encoded in exons 2-5. It was found that exon 6 , which encoded 69 amino acids, is alternatively spliced (19). Previously, we reported $\mathrm{dbpA}$ as a candidate molecule that can accelerate inflammation-induced hepatocarcinogenesis. Expression of dbpA protein is associated with the advanced steges of HCC and its nuclear localization is a marker of poor prognosis (20-22).

Most of HCCs arise from chronic hepatitis or live cirrhosis and we consider these situations to be a hypercarcinogenic state $(23,24)$. Our previous study showed that the expression of $\mathrm{dbpA}$ was significantly decreased in adjacent non-tumorous 
Table I. Clinicopathological features of 96 patients with primary HCC.

\begin{tabular}{|c|c|c|c|}
\hline Clinicopathological factor & $\operatorname{HBV}(n=15)$ & $\operatorname{HCV}(n=41)$ & $\operatorname{NBNC}(n=40)$ \\
\hline Age (years, mean \pm SD) & $54.0 \pm 12.3$ & $63.7 \pm 7.6$ & $72.3 \pm 7.9$ \\
\hline Gender (male/female) & $11 / 4$ & $32 / 9$ & $31 / 9$ \\
\hline AST (IU/1, mean \pm SD) & $38.7 \pm 27.1$ & $54.7 \pm 37.5$ & $34.5 \pm 26.8$ \\
\hline $\operatorname{ALT}(\mathrm{IU} / 1$, mean $\pm \mathrm{SD})$ & $43.0 \pm 56.9$ & $46.3 \pm 50.1$ & $29.5 \pm 26.9$ \\
\hline Plt $\left(x 10^{9} / 1\right.$, mean \pm SD $)$ & $11.0 \pm 15.4$ & $11.7 \pm 5.56$ & $17.2 \pm 8.93$ \\
\hline ICG-R15 (\%, mean \pm SD) & $14.6 \pm 6.20$ & $16.2 \pm 9.91$ & $17.6 \pm 10.7$ \\
\hline $\mathrm{PT} \%($ mean $\pm \mathrm{SD})$ & $74.4 \pm 24.4$ & $85.1 \pm 15.4$ & $86.0 \pm 11.9$ \\
\hline T.bil (mg/dl, mean \pm SD) & $0.78 \pm 0.24$ & $0.84 \pm 0.29$ & $0.80 \pm 0.39$ \\
\hline $\mathrm{Alb}(\mathrm{g} / \mathrm{dl}$, mean $\pm \mathrm{SD})$ & $4.20 \pm 0.51$ & $3.80 \pm 0.40$ & $3.94 \pm 0.42$ \\
\hline $\operatorname{AFP}(\mathrm{ng} / \mathrm{ml}, \log 10)$ & $2.58 \pm 1.50$ & $1.55 \pm 1.26$ & $0.99 \pm 1.06$ \\
\hline PIVKA-II (mAU/ml, log10) & $2.32 \pm 1.00$ & $2.00 \pm 1.08$ & $2.05 \pm 1.35$ \\
\hline Tumor max size $($ mean $\pm \mathrm{SD})$ & $4.75 \pm 4.11$ & $3.85 \pm 2.22$ & $5.20 \pm 3.80$ \\
\hline Tumor size $(\geq 2.1 \mathrm{~cm})$ & $1 / 14$ & $5 / 36$ & $4 / 36$ \\
\hline Tumor size $(\geq 5.0 \mathrm{~cm})$ & $10 / 5$ & $33 / 8$ & $19 / 21$ \\
\hline No. of tumors (A/B/C/D) & $11 / 3 / 1 / 0$ & $23 / 9 / 5 / 4$ & $28 / 5 / 3 / 4$ \\
\hline Single/Multiple & $11 / 4$ & 24/17 & $28 / 12$ \\
\hline Macro type (SN/SNEG/CM/Other) & $4 / 2 / 7 / 2$ & $20 / 12 / 5 / 4$ & $19 / 12 / 8 / 1$ \\
\hline Histological differentiation (Well/Moderate/Poor) & $2 / 10 / 3$ & $11 / 26 / 4$ & $9 / 24 / 7$ \\
\hline Growth pattern (Expansive/Invasive) & $8 / 7$ & $33 / 8$ & $38 / 2$ \\
\hline Capsular formation $(-/+)$ & $7 / 8$ & $4 / 37$ & $9 / 31$ \\
\hline Capsular invasion (-/+) & $7 / 8$ & $17 / 24$ & $17 / 23$ \\
\hline Portal vein invasion $(-/+)$ & $4 / 11$ & $23 / 18$ & $23 / 17$ \\
\hline Micro vascular invasion (-/+) & $4 / 6$ & $23 / 11$ & $23 / 11$ \\
\hline Macro vascular invasion (-/+) & $10 / 5$ & $34 / 7$ & $34 / 6$ \\
\hline Recurrence (Abcent/Present) & $11 / 4$ & $25 / 16$ & $26 / 14$ \\
\hline Stages (I/II/III/IV) & $1 / 4 / 8 / 2$ & $2 / 20 / 13 / 6$ & $1 / 20 / 13 / 6$ \\
\hline
\end{tabular}

AST, aspartate aminotransferase; ALT, alanine aminotransferase; PLT, platelet; ICG-R15, indocyanine green retention rate at 15 min; PT\%, prothrombin time; T.bil, total bilirubin; Alb, albumin; AFP, $\alpha$-fetoprotein; PIVKAII, protein induced by vitamin K absence or antagonists II; No. of tumors (A/B/C/D): A, 1; B , 2; C, 3; D , $\geq 4$; SN, single nodular type; SNEG, single nodular type with extranodular growth; CM, confluent multinodular type; +, positive; -, negative.

tissues. The regulational mechanism, however, remains unclear. Profile of the $\mathrm{CpG}$ sites in the promoter region of $\mathrm{dbpA}$ and the correlation with the level of dbpA mRNA expression, methylation status of that promoter region and correlation of clinicopathological feature in HCC are still largely unknown.

In this study, we examined the dbpA mRNA expression level by quantitative real-time reverse transcription PCR in HCC, adjacent non-tumorous tissue and normal liver tissue. We also analyzed the methylation status of promoter $\mathrm{CpG}$ island of this gene, in the same tissues and several hepatoma cell lines. The results showed the inverse correlation of the expression level and methylation status, both in cancer tissue and the corresponding non-tumorous tissues. The survival rate was more significantly associated with the low expression level of dbpA in non-tumorous tissues than in HCC tissues.

\section{Materials and methods}

Patient characteristics. We analyzed a total of 202 liver subjects, including 96 pairs of HCC and adjacent nontumorous tissues and 10 normal liver specimens. All patients underwent surgical resection in the Department of Hepato-
Biliary-Pancreatic Surgery at Tokyo Medical and Dental University Hospital between April 2003 and March 2009. This research project was approved by the local ethics committee and all samples were obtained with the patient's informed consent. Tissues were collected during surgery, snap-frozen in liquid nitrogen and then stored at $-80^{\circ} \mathrm{C}$ for DNA/RNA analysis. A part of the tissue sample was fixed in formalin and embedded in paraffin for histological diagnosis and others analyses. Histological diagnosis was made when two pathologists specializing in liver disease reached the same consensus. Hepatitis B virus (HBV) surface antigen or hepatitis $\mathrm{C}$ virus (HCV) antibody was positive in 15 or 41 patients, respectively. Forty patients were negative for both virus markers and there was no patient infected with both. The details of the clinical data from the patients, classified by virus status, are listed in Table I. All normal liver tissues were negative for both viral markers, and histology showed no evidence of fibrosis or inflammation.

DNA and RNA extraction of cell lines and tissue sample. The human hepatoma cell lines, PLC/PRF/5, SK-Hep1 and HepB3 were obtained from the American Type Culture Collection 
(Manassas, VA, USA). JHH4, JHH5, HLE, HepG2, Huh1, Huh6 and Huh7 were obtained from the Human Science Research Resources Bank (Osaka, Japan). The conditions of cell culture were reported previously (25). Total RNA was extracted from tissue specimens and human hepatoma cell lines using RNeasy mini kit (Qiagen, Valencia, CA) and treated with RNase-free DNase I according to the manufacturer's instructions. Integrity of RNA was assessed using Agilent Bioanalyzer RNA 6000 Nano Assay (Agilent Technologies, Palo Alto, CA, USA). All samples had RNA integrity number $(\mathrm{RIN})>5$.0. Total genomic DNA was extracted from cell lines and frozen tissue using a commercial DNA extraction kit (QIAamp DNA Mini Kit; Qiagen) according to the manufacturer's instructions.

Reverse transcription $(R T)$-polymerase chain reaction $(P C R)$ and real-time quantitative RT-PCR of dbpA $m R N A$. Two micrograms of total RNA, was reverse-transcribed to cDNA with High-Capacity cDNA Reverse Transcription Kit (Applied Biosytems) using the random primer contained in the kit, following the manufacturer's directions. Quantitative PCR was performed using the SYBR-Green Supermix (Bio-Rad Laboratories, Hercules, CA, USA) on the AB 7500 Fast Real-Time PCR System (Applied Biosystems) under the following conditions: $2 \mathrm{~min}$ at $50^{\circ} \mathrm{C}, 10 \mathrm{~min}$ at $95^{\circ} \mathrm{C} ; 40$ cycles of $15 \mathrm{sec}$ at $95^{\circ} \mathrm{C}$ and $60 \mathrm{sec}$ at $60^{\circ} \mathrm{C}$. A 171-bp fragment of dbpA cDNA was amplified with 25-mer sense primer in exon 5 (5'-ATGGAGTTCCTGTGGAAGGGAGTCG-3') and antisense primer in exon 6 (5'-CAGAGAACTGCCT ATCAGTGGCAGG-3'). For glyceraldehyde-3-phosphate dehydrogenase (GAPDH), 18-mer sense primer (5'-AGCCAC ATCGCTCAGACA-3') and 19-mer antisense primer (5'-GCC CAATACGACCAAATCC-3') were used. Immediately after the amplification, melting curve protocols were performed to ensure primer-dimers and other non-specific products had been minimized or eliminated. GAPDH transcript was tested as an endogenous reference to calculate the relative expression levels of target genes according to instructions of Applied Biosystems. For the quantitative analysis of specific mRNA expression, CT values were calculated using the 7500 SDS software. The PCR products were separated by gel electrophoresis and the DNA bands were visualized under ultraviolet light for photographing.

Cell culture and 5-Aza-2-deoxycytidine treatment. Hepatoma cell lines were maintained in Dulbecco's minimum essential medium (DMEM; Sigma, St. Louis, MO, USA) containing non-essential amino acid (Invitrogen, Carlsbad, CA, USA) and $10 \%$ heat-inactivated fetal bovine serum (FBS, JRH Bioscience, Lenexa, $\mathrm{KS}, \mathrm{USA}$ ); and grown at $37^{\circ} \mathrm{C}$ in $5 \% \mathrm{CO}_{2}$. After a 48 -h incubation in normal medium, cell lines were treated with a demethylating agent, $5 \mu \mathrm{M}$ 5-Aza-2-deoxycytidine (5-AzaCdR; Sigma) for the following 3 days, and the medium and the drug were replaced every $24 \mathrm{~h}$. As a control, cell lines were cultured in normal medium which was replaced every $24 \mathrm{~h}$.

Sodium bisulfite modification, sequencing and methylationspecific PCR. Bisulfite modification of extracted DNA ( $2 \mu \mathrm{g})$ was performed using the EpiTect ${ }^{\circledR}$ Bisulfite Kit (Qiagen, Hilden, Germany) according to the manufacturer's instructions. We searched $\mathrm{CpG}$ islands in the dbpA promoter region (from -500 to $+500 \mathrm{bp}$ ) (GenBank accession no. AH003216) using CpG Island searcher (http://www.cpgislands.com) with the default setting (\% GC11 >55\%, ObsCpG/ExpCpG >0.65). The primers were designed by Methyl Primer Express v1.0 software (Applied Biosytems). Sodium bisulfite-treated DNA was amplified by FastStart HiFi PCR System (Roche Applied Science, Germany) for region $(-258$ to +178$)$ of dbpA gene. The primers were BSF1 (5'-GGGGATCCTGGTTTTTTTTGGT TTTGTAAG-3'), BSR1 (5'-GGAAGCTTTCCTCTACTCTC GCTCAAAC-3'), BSF2 (5'-GGGGATCCTTGAGGGAGGA GAGTTTAATGTATTT-3') and BSR25 (5'-GGAAGCTTCC CTAAACCTCTCATTAACATTTAAAA-3').

The PCR conditions were as follows: 2 min at $95^{\circ} \mathrm{C}, 35$ cycles of $30 \mathrm{sec}$ at $95^{\circ} \mathrm{C}, 30 \mathrm{sec}$ at $58^{\circ} \mathrm{C}$ and $1 \mathrm{~min}$ at $72^{\circ} \mathrm{C}$, and final $72^{\circ} \mathrm{C}$ for $3 \mathrm{~min}$. The PCR products were then subcloned into the basic pBluescript II SK (+) vector. Then, we picked 10 independent colonies for each case, determined the sequence of the promoter in each plasmid by ABI PRISM $310 \mathrm{v} 3.0$ Sequence analyzer and examined the extent of methylation by counting the number of methylated cytosine residues.

The methylation status of the dbpA promoter in hepatoma cell lines, 61 paired HCC and normal liver specimens was examined by methylation-specific PCR according to Herman et al (26). The first $174 \mathrm{bp}$ containing $17 \mathrm{CpG}$ sites was amplified with a pair of methylation-specific (forward, 5'-GTTTTGTAAGCGATTCGC-3'; reverse, 5'-AAATTTTTC TAAACGACGCA-3') or non-methylation-specific (forward, 5'-TTGGTTTTGTAAGTGATTTGT-3'; reverse, 5'-AAATTT TTCTAAACAACACACCA-3') primer sets. The second $170 \mathrm{bp}$ containing $28 \mathrm{CpG}$ sites was amplified with the methylationspecific forward primer, 5'-AGCGAGGAGTTTAAGGAGC-3'; the reverse primer, 5'-TCGATAACGATTAATCGACG-3'; the unmethylation-specific forward primer, 5'-GAGTGAGGAGT TTAAGGAGT-3' and the reverse primer 5'-CTCAATAACAA TTAATCAACA-3'. After heating at $95^{\circ} \mathrm{C}$ for $10 \mathrm{~min}$, PCR was performed with FastStart HiFi PCR System containing $2.5 \mathrm{U}$ of FastStart High Fidelity Enzyme Blend and in a thermal cycler (GeneAmp PCR System 9700; Applied Biosystems) for 35 cycles, each consisted of denaturation at $95^{\circ} \mathrm{C}$ for $15 \mathrm{sec}$, annealing at $58^{\circ} \mathrm{C}$ for $60 \mathrm{sec}$ and extension at $72^{\circ} \mathrm{C}$ for $30 \mathrm{sec}$ and final 3-min extension at $72^{\circ} \mathrm{C}$. The PCR products were electrophoresed on $2 \%$ agarose gels.

Statistical analyses of clinicopathological correlation. Statistical analyses were performed using PASW Statistics 18 software for Windows (IBM). Difference in mRNA levels between groups, were analyzed using the Student's t-test. Fisher's exact test was performed to estimate the significance of gene expression differences between categorical and noncategorical data for each group. The overall survival curve and disease-free survival rate was calculated by the KaplanMeier method and rates were reported with $95 \%$ confidence intervals. Differences were tested for significance using the log-rank test. $\mathrm{P}<0.05$ was deemed to be statistically significant.

\section{Results}

Level of mRNA for dbpA in HCC and adjacent non-tumor tissues. A total of 202 qRT-PCR data was normalized with expression of control gene and the estimated gene expression 


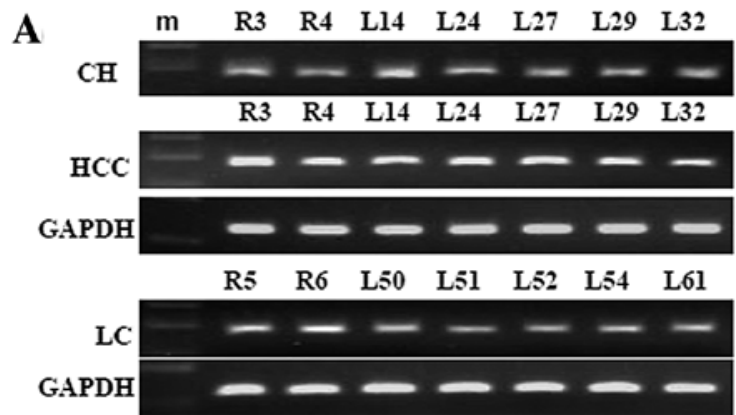

B

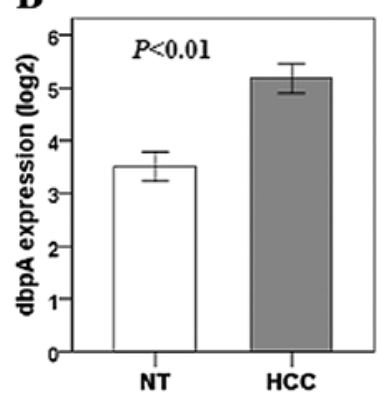

D
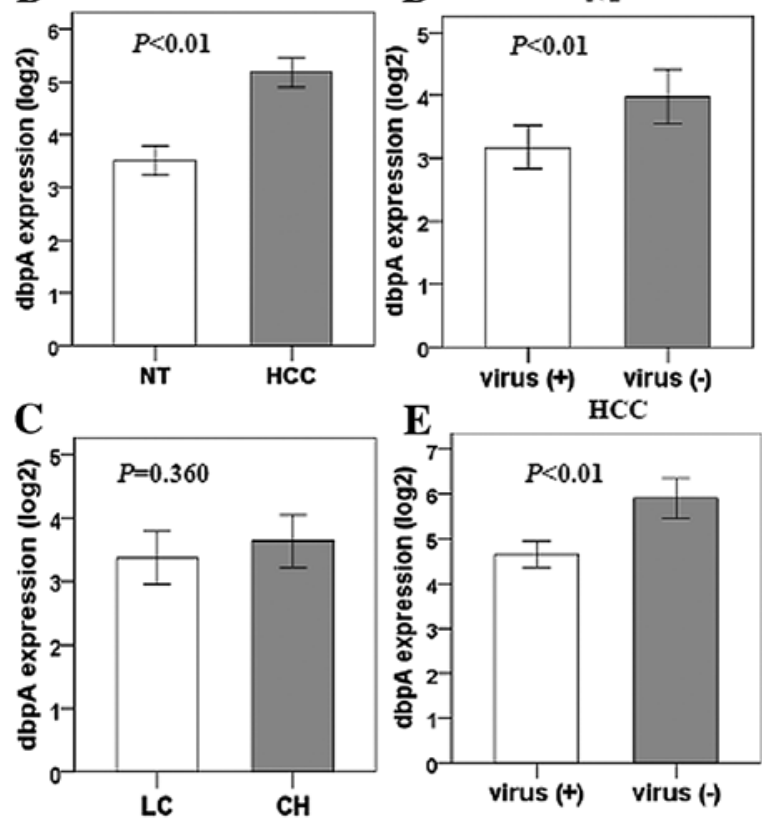

Figure 1. RT-PCR and qRT-PCR analysis of dbpA mRNA in HCC and noncancerous liver specimens. (A) RT-PCR products were detected in agorose gel electrophoreses. (B) mRNA expression levels of dbpA were compared between HCC and adjacent non-cancerous tissues (NT), (C) between chronic hepatitis and cirrhosis, (D) between virus associated and non-associated NTs, (E) between virus associated and non-associated HCCs. NT, non-tumor; HCC, hepatocellular carcinoma; $\mathrm{CH}$, chronic hepatitis; LC, cirrhosis.

levels were $\log 2$-transformed. After the quantitative PCR, the results of the agarose gel electrophoresis confirmed that specific product about $171 \mathrm{bp}$ and no non-specific products were obtained upon amplification of dbpA (Fig. 1A). The differences in mRNA expression levels for $\mathrm{dbpA}$ were statistically significant between HCC and corresponding non-tumorous liver (5.18 \pm 1.36 vs. $3.51 \pm 1.36 ; \mathrm{P}<0.01)$ (Fig. 1B), There were no statistical significance between chronic hepatitis and cirrhosis (3.63 \pm 1.45 vs. $3.37 \pm 1.28 ; \mathrm{P}=0.360)$ (Fig. 1C). dbpA mRNA was more highly expressed in the virus-negative cases than those associated with $\mathrm{HBV}$ or $\mathrm{HCV}$ infection, both in $\mathrm{HCC}$ (5.91 \pm 1.41 vs. $4.66 \pm 1.06$; $\mathrm{P}<0.01)$ (Fig. $1 \mathrm{E}$ ) and adjacent nontumorous tissue $(3.98 \pm 1.35$ vs. $3.18 \pm 1.27$; $\mathrm{P}<0.01)$ (Fig. 1D). There were no statistical significance between HBV and HCV backgrounds in non-tumorous liver $(2.66 \pm 1.47$ vs. $3.37 \pm 1.12$; $\mathrm{P}=0.106)$ or $\mathrm{HCC}(4.66 \pm 0.76$ vs. $4.66 \pm 1.16 ; \mathrm{P}=0.959)$, respectively.

Overexpression of dbpA in non-cancerous tissues is associated with poor prognosis in patients with HCC. The correlations of
dbpA mRNA expression with clinicopathological characters were analyzed both in HCC and the adjacent non-tumorous tissues of 96 HCC patients. Depending on the expression level of dbpA mRNA, the tissue samples were divided into two groups, $\mathrm{H}$ or L; H group showing higher mRNA level than the average and $\mathrm{L}$ group lower than that. As shown in Table II, there was no statistically significant difference of $\mathrm{dbpA}$ expression levels between each categorical clinicopathological group such as age, gender, size of tumor, vessel invasion, stages and others except viral backgrounds. High dbpA expression level was significantly associated with low serum level of protein induced by vitamin $\mathrm{K}$ absence or antagonist-II (PIVKAII) $(\mathrm{P}=0.040)$.

We further explored whether the expression of $\mathrm{dbpA}$ mRNA levels was associated with the survival rates of HCC patients. All patients were followed up until the end-point of the research. Median of the follow-up period was 12.3 months (range, 0.1-59.2 months) and the result showed 23 of 96 patients died. High dbpA expression was associated with the poor prognosis both in overall- and recurrence-free survival rates. This tendency was more obvious and statistically significant in the patients whose non-tumorous tissues showed the high dbpA expression (Fig. 2A and B). The patients with high dbpA expression in HCC tissues also showed poor prognosis, but the difference was not statistically significant (Fig. 2C and D).

Induction of $d b p A$ gene expression by 5-Aza- $d C$. The expression level of dbpA mRNA was evaluated in 13 HCC cell lines. Quantitative real-time RT-PCR analysis showed that there was higher mRNA expression of dbpA in 9 of 13 HCC cell lines (Fig. 3A). Similar results were also observed in Western blot analysis (data not shown). To verify the role of DNA methylation in the regulation of $\mathrm{dbpA}$ expression 8 hepatoma cell lines (JHH1, JHH2, JHH4, HLE, HLF, HepG2, Hep3B and Huh7) were treated with 5-Aza-dC, and then dbpA expression was examined (Fig. 3B). In 6 of 8 cell lines, dbpA expression was significantly up-regulated by 5 -Aza-dc treatment (1.4- to 10.1-fold difference) (Fig. 3C), which indicated that silencing of $\mathrm{dbpA}$ expression was through hypermethylation of $\mathrm{dbpA}$ gene promoter in certain HCC cells.

DNA methylation profile of the CpG islands in the dbpA promoter region. The search for $\mathrm{CpG}$ Islands in the $\mathrm{dbpA}$ promoter region (Fig. 4A) indicated that the main $\mathrm{CpG}$ sites were located in the -258 to -133 region upstream of the transcription start site and +33 to +178 downstream of the transcription start site. The typical $55 \mathrm{CpG}$ sites were located in this region (Fig. 4B). To examine the correlation between DNA methylation and $\mathrm{dbpA}$ expression, we further investigated the methylation status of dbpA promoter region in cell lines and liver tissues by bisulfite genomic sequencing shown in Fig. 4C.

Methylation analyses of dbpA promoter in HCC and adjacent non-tumor tissues. MS-PCR was done in 61 paired samples of HCC patients and 10 normal liver specimens. Methylation of CpG island was detected in 23 out of 61 (37.7\%) HCC tissues, 30 out of $61(49.2 \%)$ adjacent non-tumor and not detected in any of the normal liver tissues (representative data shown in Fig. 4D). Then, we analyzed the relationship of mRNA levels and methylation status of $\mathrm{dbpA}$ in HCC and non-tumor tissues. 
Table II. dbpA expression and clinicopathological findings in HCC patients.

\begin{tabular}{|c|c|c|c|c|c|c|}
\hline \multirow[b]{3}{*}{ Clinicopathological factor } & \multicolumn{6}{|c|}{ dbpA expression } \\
\hline & \multicolumn{2}{|c|}{ Non-cancerous } & \multirow[b]{2}{*}{ P-value } & \multicolumn{2}{|c|}{$\mathrm{HCC}$} & \multirow[b]{2}{*}{ P-value } \\
\hline & Low & High & & Low & High & \\
\hline \multicolumn{7}{|l|}{ Age (years) } \\
\hline$<60$ & 13 & 7 & \multirow[t]{2}{*}{0.130} & 11 & 9 & \multirow[t]{2}{*}{1.000} \\
\hline$\geq 60$ & 33 & 43 & & 41 & 35 & \\
\hline \multicolumn{7}{|l|}{ Gender } \\
\hline Male & 32 & 42 & \multirow[t]{2}{*}{0.144} & 40 & 34 & \multirow[t]{2}{*}{1.000} \\
\hline Female & 14 & 8 & & 12 & 10 & \\
\hline \multicolumn{7}{|l|}{ No. of tumor } \\
\hline Solitary & 30 & 33 & \multirow[t]{2}{*}{1.000} & 34 & 29 & \multirow[t]{2}{*}{1.000} \\
\hline Multiple & 16 & 17 & & 18 & 15 & \\
\hline \multicolumn{7}{|l|}{ Virus infection } \\
\hline Negative & 14 & 26 & \multirow[t]{2}{*}{$0.039^{\mathrm{a}}$} & 15 & 25 & \multirow[t]{2}{*}{$0.007^{\mathrm{a}}$} \\
\hline Positive & 32 & 24 & & 37 & 19 & \\
\hline \multicolumn{7}{|l|}{ Child-Pugh classification } \\
\hline A & 36 & 45 & \multirow[t]{2}{*}{0.160} & 42 & 39 & \multirow[t]{2}{*}{0.400} \\
\hline $\mathrm{B}$ & 10 & 5 & & 10 & 5 & \\
\hline Tumor size $(\mathrm{cm})$ & & & & & & \\
\hline$<5.0$ & 31 & 31 & 0.671 & 33 & 29 & 0.833 \\
\hline$\geq 5.0$ & 15 & 19 & & 19 & 15 & \\
\hline AFP (ng/ml) & & & & & & \\
\hline$<400$ & 38 & 40 & 0.798 & 41 & 37 & 0.604 \\
\hline$\geq 400$ & 8 & 10 & & 11 & 7 & \\
\hline PIVKAII (mAU/ml) & & & & & & \\
\hline$<100$ & 20 & 25 & 0.546 & 19 & 26 & $0.040^{\mathrm{a}}$ \\
\hline$\geq 100$ & 26 & 25 & & 33 & 18 & \\
\hline Macro type of tumor & & & & & & \\
\hline $\mathrm{SN}$ & 21 & 22 & 0.527 & 23 & 20 & 0.758 \\
\hline SNEG & 13 & 13 & & 13 & 13 & \\
\hline $\mathrm{CM}$ & 7 & 13 & & 13 & 7 & \\
\hline Degree of differentiation & & & & & & \\
\hline Well & 11 & 11 & 0.359 & 11 & 11 & 0.523 \\
\hline Moderate & 26 & 34 & & 35 & 25 & \\
\hline Poor & 9 & 5 & & 6 & 8 & \\
\hline Portal vein invasion & & & & & & \\
\hline Absent & 27 & 23 & 0.228 & 26 & 24 & 0.686 \\
\hline Present & 19 & 27 & & 26 & 20 & \\
\hline Formation of capsule & & & & & & \\
\hline pfc (-) & 9 & 11 & 0.806 & 7 & 13 & 0.077 \\
\hline pfc $(+)$ & 37 & 39 & & 45 & 31 & \\
\hline Infiltration to capsule & & & & & & \\
\hline pfc-inf (-) & 18 & 23 & 0.540 & 21 & 20 & 0.681 \\
\hline pfc-inf (+) & 28 & 27 & & 31 & 24 & \\
\hline TNM stage & & & & & & \\
\hline $\mathrm{I}+\mathrm{II}$ & 26 & 22 & 0.307 & 26 & 22 & 1.000 \\
\hline III+IV & 20 & 28 & & 26 & 22 & \\
\hline Recurrence of tumor & & & & & & \\
\hline Absent & 32 & 28 & 0.208 & 36 & 24 & 0.147 \\
\hline Present & 14 & 22 & & 16 & 20 & \\
\hline
\end{tabular}

AFP, $\alpha$-fetoprotein; PIVKAII, protein induced by vitamin K absence or antagonists II; SN, single nodular type; SNEG, single nodular type with extranodular growth; $\mathrm{CM}$, confluent multinodular type. ${ }^{\mathrm{a}} \mathrm{P}<0.05$. 

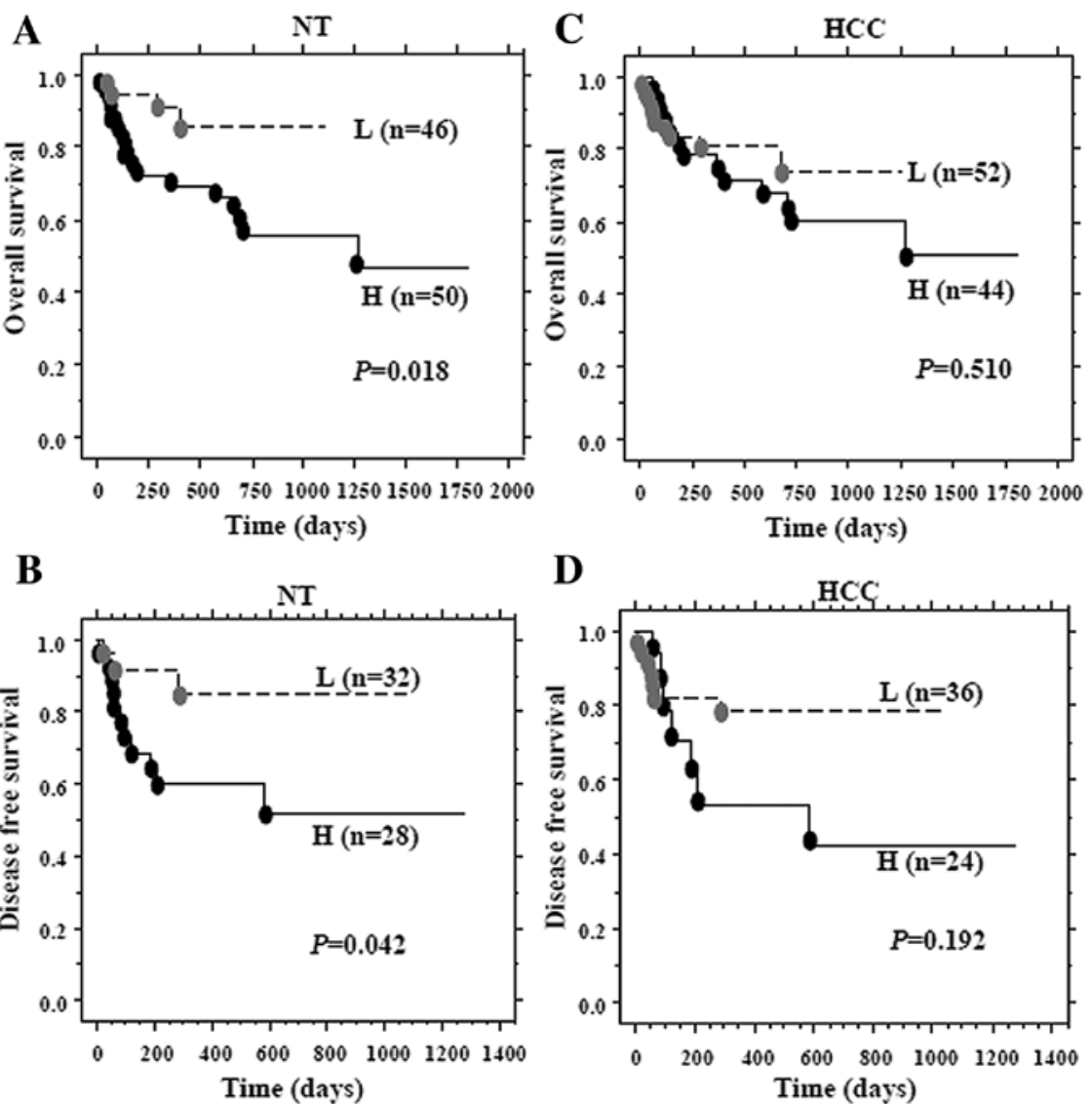

Figure 2. Cumulative overall survival curves (A, C) and tumor recurrence-free survival curves (B, D) of HCC patients after curative resection. Effect of dbpA expression level (High vs. Low) in NT (A, B) or in HCC (C, D) for survival curves are shown. Survival rate of patients with High or Low dbpA expression are indicated by solid or dotted lines, respectively.
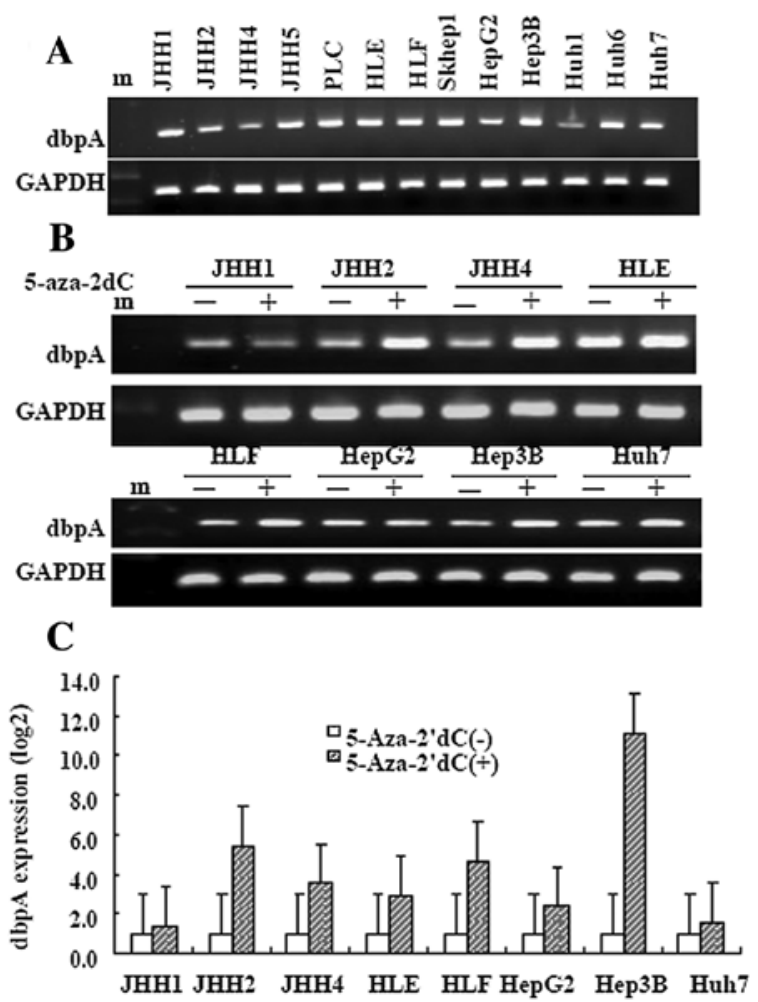

Figure 3. dbpA expression in HCC cell lines. The expression of dbpA mRNA in hepatoma cell lines (A) and effect of 5-Aza-2'dC on dbpA expression (B) are shown. (C) dbpA mRNA was quantified by qRT-PCR.
In HCC, dbpA mRNA levels were significantly higher in the samples with unmethylated promoter than in those with methylated one $(5.02 \pm 1.01$ vs. $6.11 \pm 1.37 ; \mathrm{P}<0.01)$. In non-tumorous samples, there was similar tendency but the difference was not statistically significant ( $3.65 \pm 1.33$ vs. $4.10 \pm 1.34 ; \mathrm{P}=0.194$ ). Next we analyzed viral or non-viral related patients that the expression levels of dbpA and the methylation status. The results show (Fig. 5D) that the expression more significantly correlated with non-viral related HCC than viral HCC $(5.05 \pm 1.13$ vs. $6.67 \pm 1.26 ; \mathrm{P}=0.001)$ patients in the methylation or unmethylation status, respectively. Fig. $5 \mathrm{E}$ shows the representative data of dbpA mRNA expression in the samples with the methylated promoter and those with the unmethylated promoter. Table III shows the association of dbpA promoter methylation and clinicopathological characteristics in $61 \mathrm{HCC}$ patients. Methylated dbpA promoter in the non-tumorous part of HCC was more frequently observed in patients with low serum level of AFP $(<400 \mathrm{ng} / \mathrm{ml})$ than patients with high serum level of AFP ( $\geq 400 \mathrm{ng} / \mathrm{ml})(57.1$ vs. $16.7 \% ; \mathrm{P}=0.022)$. Methylated dbpA promoter in HCC tissue was more frequently observed in female than male patients ( 73.3 vs. $26.1 \% ; \mathrm{P}=0.002$ ). Poorly differentiated HCC (88.9\%; $\mathrm{P}=0.041)$, and low serum level of PIVKAII ( $<100 \mathrm{mAU} / \mathrm{ml})(76.7 \%$; $\mathrm{P}=0.034)$ were also associated with the demethylated dbpA promoter in HCC tissues. There was no association between dbpA promoter methylation and age, tumor size, vascular invasion, stages, recurrence of tumor and other factors. 
$\mathbf{A}$

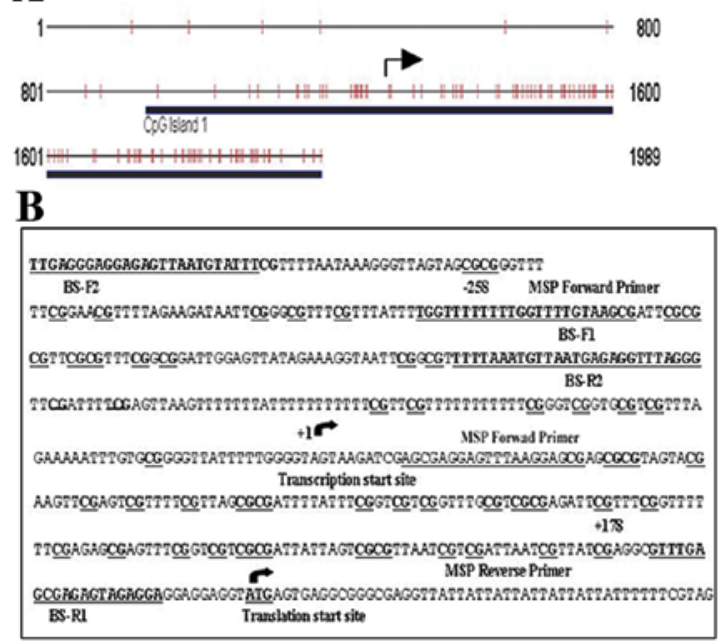

$\mathbf{C}$

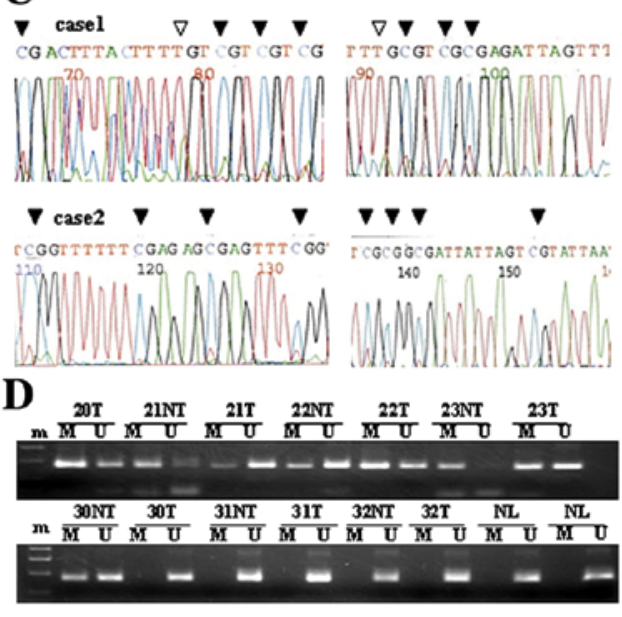

Figure 4. Methylation analyzed of dbpA promoter in liver tissue of HCC patients. (A) The CpG island was identified by CpG Island Searcher. The transcription start site is indicated by an arrow. (B) Sequence of the dbpA minimal promoter region $(-305$ to +262$)$ and the relative location of primer for bisulfite sequencing PCR and MS-PCR. (C) Representative data of dbpA promoter sequence after bisulfite modification. (D) MS-PCR analysis of dbpA promoter in HCC and normal tissues. M, methylated; U, unmethylated. Black arrow head ( $\mathbf{v})$, methylated; white arrow head $(\nabla)$, unmethylated.
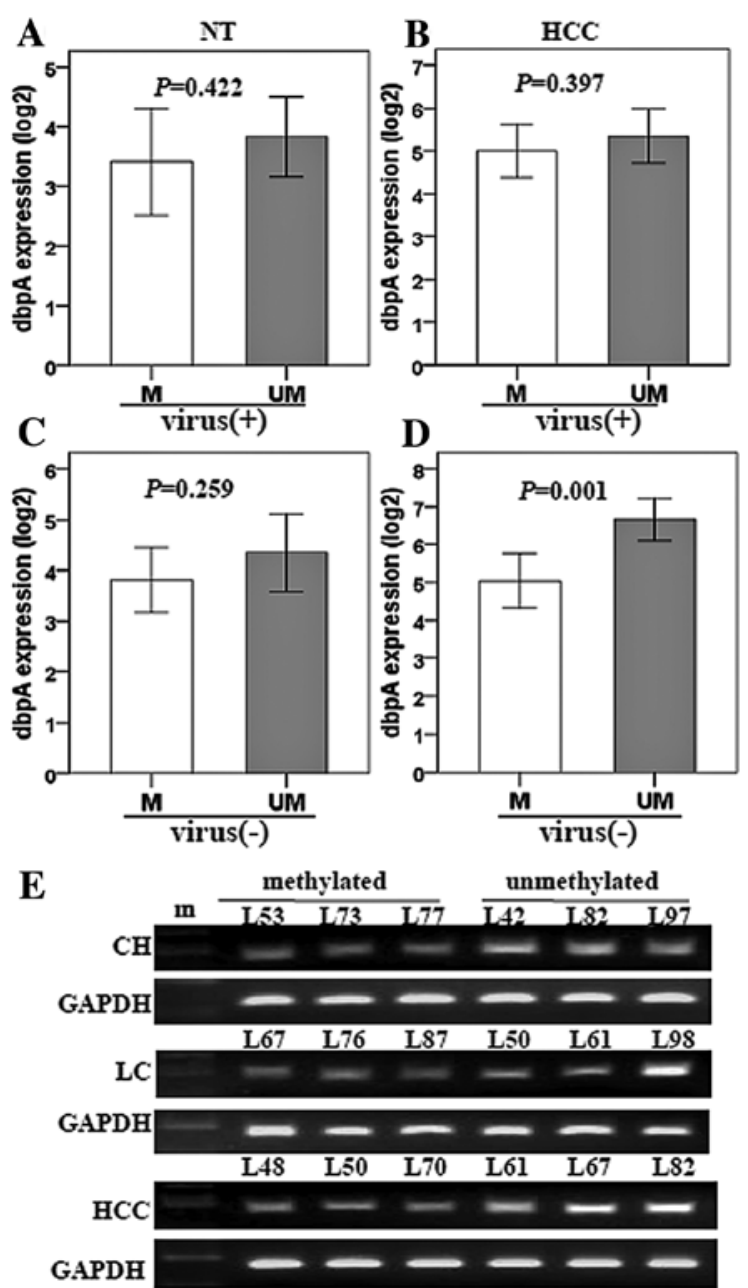

Figure 5. Relationship of dbpA mRNA expression and the promoter methylation status in NT (A, C) and HCC (B, D). The results of samples including viral cases $(\mathrm{A}, \mathrm{B})$ and non-viral cases $(\mathrm{C}, \mathrm{D})$ are shown. (E) The methylation or unmethylation of patient mRNA expression levels were detected in agarose gel electrophoresis.

\section{Discussion}

We showed that the expression of dbpA mRNA was higher in HCC tissue than in the adjacent non-cancerous part. Unexpectedly, the high dbpA expression level in non-cancerous tissues, but not in HCC, was associated with the poor prognosis of patients (Fig. 2A and B). This result is compatible with our previous study reporting no association of dbpA protein expression in $\mathrm{HCC}$ tissue with prognosis of patients, although the nuclear localization of dbpA protein was related to poor prognosis (22). At that time we were not able to analyze the dbpA expression in the non-cancerous tissues.

Profile of the CpG sites in the promoter region of dbpA, their methylation status, and their correlation with the clinicopathological features in human hepatocellular carcinoma are still largely unknown. Our previous and present studies showed up-regulation of dbpA mRNA and protein in HCC tissues, suggesting that the dbpA expression is regulated at the transcriptional level. In this study, 9 of 13 human HCC cell lines showed enhanced expression of dbpA mRNA. The increase of $\mathrm{dbpA}$ expression by the treatment with 5-Aza-2dC indicated that hypomethylation of $\mathrm{dbpA}$ promoter region was a key contributor to the increased dbpA expression in some cell lines. The regulatory regions of the dbpA genes are highly GC-rich without the typical TATA box. There are two Sp1-binding sequences, CCGCCC and CCACCC at nucleotides $-58,-75$. Many genes that regulate the cell cycle frequently contain proximal GC-rich promoter sequences, and their interactions with SP proteins and other transcription factors are critical for their expression (27). Sp1 is associated with the prognosis of cancers, including pancreatic cancer (28), breast cancer (29) and gastric cancer (30), although the potential role of Sp1 in HCC prognosis remains unclear. The increased expression of SP1 may be another factor up-regulating the dbpA expression in HCC. 
Table III. Association between methylation status of dbpA and clinicopathological parameters in HCC.

\begin{tabular}{|c|c|c|c|c|c|c|c|}
\hline \multirow[b]{2}{*}{ Characteristics } & \multirow[b]{2}{*}{$\mathrm{N}$} & \multicolumn{2}{|c|}{ Non-cancerous } & \multirow[b]{2}{*}{ P-value } & \multicolumn{2}{|c|}{$\mathrm{HCC}$} & \multirow[b]{2}{*}{ P-value } \\
\hline & & M & UM & & $\mathrm{M}$ & UM & \\
\hline \multicolumn{8}{|l|}{ Age (years) } \\
\hline$<60$ & 10 & 4 & 6 & \multirow[t]{2}{*}{0.731} & 4 & 6 & \multirow[t]{2}{*}{1.000} \\
\hline$\geq 60$ & 51 & 26 & 25 & & 19 & 32 & \\
\hline \multicolumn{8}{|l|}{ Gender } \\
\hline Male & 46 & 20 & 26 & \multirow[t]{2}{*}{0.146} & 12 & 34 & \multirow[t]{2}{*}{$0.002^{\mathrm{a}}$} \\
\hline Female & 15 & 10 & 5 & & 11 & 4 & \\
\hline \multicolumn{8}{|l|}{ No. of tumors } \\
\hline Solitary & 40 & 20 & 20 & \multirow[t]{2}{*}{1.000} & 13 & 27 & \multirow[t]{2}{*}{0.277} \\
\hline Multiple & 21 & 10 & 11 & & 10 & 11 & \\
\hline \multicolumn{8}{|l|}{ Tumor size $(\mathrm{cm})$} \\
\hline$<5.0$ & 39 & 19 & 20 & \multirow[t]{2}{*}{1.000} & 13 & 26 & \multirow[t]{2}{*}{0.415} \\
\hline$\geq 5.0$ & 22 & 11 & 11 & & 10 & 12 & \\
\hline \multicolumn{8}{|l|}{$\operatorname{AFP}(\mathrm{ng} / \mathrm{ml})$} \\
\hline$<400$ & 49 & 28 & 21 & \multirow[t]{2}{*}{$0.022^{\mathrm{a}}$} & 17 & 32 & \multirow[t]{2}{*}{0.342} \\
\hline$\geq 400$ & 12 & 2 & 10 & & 6 & 6 & \\
\hline \multicolumn{8}{|c|}{ PIVKAII (mAU/ml) } \\
\hline$<100$ & 30 & 14 & 16 & \multirow[t]{2}{*}{0.800} & 7 & 23 & \multirow[t]{2}{*}{$0.034^{\mathrm{a}}$} \\
\hline$\geq 100$ & 31 & 16 & 15 & & 16 & 15 & \\
\hline \multicolumn{8}{|l|}{ Differentiation } \\
\hline Well & 15 & 9 & 6 & \multirow[t]{3}{*}{0.504} & 9 & 6 & \multirow[t]{3}{*}{$0.041^{\mathrm{a}}$} \\
\hline Moderate & 37 & 16 & 21 & & 12 & 25 & \\
\hline Poor & 9 & 5 & 4 & & 1 & 8 & \\
\hline Portal vein inva & & & & & & & \\
\hline Absent & 34 & 17 & 17 & 1.000 & 14 & 20 & 0.601 \\
\hline Present & 27 & 13 & 14 & & 9 & 18 & \\
\hline Hepatic vein inv & & & & & & & \\
\hline Absent & 53 & 26 & 27 & 1.000 & 19 & 34 & 0.461 \\
\hline Present & 8 & 4 & 4 & & 4 & 4 & \\
\hline TNM stage & & & & & & & \\
\hline I+II & 32 & 16 & 16 & 1.000 & 12 & 20 & 1.000 \\
\hline $\mathrm{III}+\mathrm{IV}$ & 29 & 14 & 15 & & 11 & 18 & \\
\hline Recurrence & & & & & & & \\
\hline Absent & 36 & 18 & 18 & 1.000 & 14 & 22 & 1.000 \\
\hline Present & 25 & 12 & 13 & & 9 & 16 & \\
\hline
\end{tabular}

NT, adjacent non-tumor tissue; HCC, hepatocellular carcinoma; AFP, $\alpha$-fetoprotein; PIVKAII, protein induced by vitamin K absence or antagonists II; M, methylation; UM, unmethylation. ${ }^{\mathrm{a}} \mathrm{P}<0.05$.

We studied the effect of HBV/HCV infection on the dbpA mRNA expression and promoter methylation. The dbpA expression level was higher in virus negative cases than in positive cases, both in NT and HCC parts $(\mathrm{P}<0.01$; Fig. 1D and $\mathrm{E}$ ). There was no difference in the $\mathrm{dbpA}$ expression level between HBV and HCV positive cases (data not shown). In virus-negative cases, the dbpA expression level in $\mathrm{HCC}$ was lower in the cases with methylated $\mathrm{dbpA}$ promoter than those with unmethylated one $(\mathrm{P}<0.01$; Fig. 5D). These data revealed that the effect of $\mathrm{dbpA}$ promoter hypomethylation on the enhanced expression is more obvious in the virus negative cases than in the positive ones. At present we cannot explain these findings, but there are several possibilities. First, in HBV/ $\mathrm{HCV}$ positive cases, the mechanisms other than promoter methylation may be regulating the dbpA expression. Second, in $\mathrm{HBV} / \mathrm{HCV}$ negative cases, another unknown carcinogenic factor is acting on the promoter demethylation and enhanced expression of dbpA. Further study is required to verify these possibilities.

The methylated dbpA promoter in non-tumorous parts, but not in HCC parts was associated with low serum level of $\alpha$-fetoprotein (Table II). The significant association of $\mathrm{dbpA}$ 
methylation and AFP levels suggests that dbpA methylation status might have potential as a diagnostic marker in HCC. The up-regulation of $\mathrm{dbpA}$ and renewed AFP expression in HCC may be the common consequence of tumorigenesis and progression. In the promoter region of $\alpha$-fetoprotein there are two 'inverted CCAAT', the core sequence of Y-box. However, we do not have the functional data to link AFP expression and that the dbpA could positively regulate the expression of the $\alpha$-fetoprotein gene. Further study is necessary to clarify the AFP expression and methylation of $\mathrm{dbpA}$, and global analysis will be of increasing importance in the identification of novel hypomethylated genes in HCC.

Regardless of etiology, most of HCC occurs through chronic hepatitis or liver cirrhosis, and these situations are considered to be hypercarcinogenic states $(23,24)$. In hypercarcinogenic states, inflammation-induced genetic and epigenetic changes are accumulated to promote hepatocarcinogenesis. Our study showed that the high $\mathrm{dbpA}$ expression in non-cancerous tissue was associated with the poor prognosis of patients and the results suggested that the demethylation related up-regulation of dbpA in hypercarcinogenic states may be accelerating hepatocarcinogenesis. The $\mathrm{dbpA}$ expression in chronic hepatitis or liver cirrhosis could be a marker to predict the occurrence of $\mathrm{HCC}$ or the prognosis of $\mathrm{HCC}$ patients.

\section{Acknowledgements}

This study was supported by Special Coordination Funds for Promoting Science and Technology (Japan Science and Technology Agency) and a Grant-in-Aid from Ministry of Education, Culture, Sports, Science and Technology of Japan.

\section{References}

1. Farazi PA and DePinho RA: Hepatocellular carcinoma pathogenesis: from genes to environment. Nat Rev Cancer 6: 674-687, 2006.

2. But DY,Lai CL and Yuen MF: Natural history of hepatitis-related hepatocellular carcinoma. World J Gastroenterol 14: 1652-1656, 2008.

3. Tang ZY, Ye SL, Liu YK, et al: A decade's studies on metastasis of hepatocellular carcinoma. J Cancer Res Clin Oncol 130: 187-196, 2004

4. Deuffic S, Poynard T, Buffat L and Valleron AJ: Trends in primary liver cancer. Lancet 351: 214-215, 1998.

5. El-Serag HB and Mason AC: Rising incidence of hepatocellular carcinoma in the United States. N Engl J Med 340: 745-750, 1999.

6. Chen CJ, Yu MW and Liaw YF: Epidemiological characteristics and rick factors of hepatocellular carcinoma. J Gastroenterol Hepatol 12: S294-S308, 1997.

7. Montesano R, Hainaut P and Wild CP: Hepatocellular carcinoma: from gene to public health. J Natl Cancer Inst 89: 1844-1851, 1997.

8. Thorgeirsson SS and Grisham JW: Molecular pathogenesis of human hepatocellular carcinoma. Nat Genet 31: 339-346, 2002.

9. Herman JG and Baylin SB: Gene silencing in cancer in association with promoter hypermethylation. N Engl J Med 349: 2042-2054, 2003.
10. Jones PA and Baylin SB: The fundamental role of epigenetic events in cancer. Nat Rev Genet 3: 415-428, 2002.

11. Jones PA and Baylin SB: The epigenomics of cancer. Cell 128: 683-692, 2007.

12. Dunn BK: Hypomethylation: one side of a larger picture. Ann N Y Acad Sci 983: 28-42, 2003.

13. Esteller M: Dormant hypermethylated tumor suppressor genes: questions and answers. J Pathol 205: 172-180, 2005.

14. Herath NI, Leggett BA and MacDonald GA: Review of genetic and epigenetic alterations in hepatocarcinogenesis. J Gastroenterol Hepatol 21: 15-21, 2006.

15. Esteller M: Aberrant DNA methylation as a cancer-inducing mechanism. Annu Rev Pharmacol Toxicol 45: 629-656, 2005.

16. Luczak MW and Jagodzinski PP: The role of DNA methylation in cancer development. Folia Histochem Cytobiol 44: 143-154, 2006.

17. Baylin SB and Ohm JE: Epigenetic gene silencing in cancer a mechanism for early oncogenic pathway addiction? Nat Rev Cancer 6: 107-116, 2006.

18. Nishida N, Nagasaka T, Nishimura T, Ikai I, Boland CR and Goel A: Aberrant methylation of multiple tumor suppressor genes in aging liver, chronic hepatitis, and hepatocellular carcinoma. Hepatology 47: 908-918, 2008.

19. Shinichi K, Marie-Genevieve M and Minoru F: Characterization of the gene for dbpA, a family member of the nucleic-acidbinding proteins containing a cold shock domain. Eur J Biochem 231: 72-82, 1995.

20. Kajino K, Yamamoto T, Hayashi J, Umeda T, Takahara T and Hino O: Recombination hot spot of Hepatitis B virus genome bind to members of the HMG domain protein family and the $\mathrm{Y}$ box protein binding protein family, implication of these proteins in genomic instability. Intervirology 44: 311-316, 2001.

21. Arakawa Y, Kajino K, Kano S, et al: Transcription of dbpA, a $\mathrm{Y}$ box binding protein, is positively regulated by E2F1: implications in hepatocarcinogenesis. Biochem Biophys Res Commun 322: 297-302, 2004

22. Mahmut Y, Kajino K, Kano S, et al: The up-regulation of Y box binding proteins (DNA binding protein $\mathrm{A}$ and Y-box binding protein-1) as prognostic marker of hepatocellular carcinoma. Clin Cancer Res 11: 7354-7361, 2005.

23. Hino O, Kajino K, Umeda T and Arakawa Y: Understanding the hypercarcinogenic state in chronic hepatitis: a clue to the prevention of human hepatocellular carcinoma. J Gastroenterol 37: 883-887, 2002.

24. Umeda T and Hino O: Molecular aspects of human hepatocarcinogenesis mediated by inflammation: from hypercarcinogenic state to normo- or hypocarcinogenic state. Oncology 62: 38-42, 2002.

25. Mahmut Y, Hiroshi M, Kaoru M, et al: Expression of Aurora B and alternative variant forms in hepatocellular carcinoma and adjacent tissue. Cancer Sci 100: 472-480, 2009.

26. Herman JG, Graff JR, Myöhänen S, Nelkin BD and Baylin SB: Methylation specific PCR: a novel PCR assay for methylation status of CpG islands. Proc Natl Acad Sci USA 93: 9821-9826, 1996.

27. Safe S and Abdelrahim M: Sp transcription factor family and its role in cancer. Eur J Cancer 41: 2438-2448, 2005.

28. Abdelrahim M, Smith R III, Burghardt R and Safe S: Role of Sp proteins in regulation of vascular endothelial growth factor expression and proliferation of pancreatic cancer cells. Cancer Res 64: 6740-6749, 2004.

29. Zannetti A, Del Vecchio S, Carriero MV, et al: Coordinate up-regulation of Sp1 DNA-binding activity and urokinase receptor expression in breast carcinoma. Cancer Res 60: 1546-1551, 2000.

30. Yao JC, Wang L, Wei D, et al: Association between expression of transcription factor Sp1 and increased vascular endothelial growth factor expression, advanced stage, and poor survival in patients with resected gastric cancer. Clin Cancer Res 10: 4109-4117, 2004. 